\title{
Catalytic mTOR inhibitors can overcome intrinsic and acquired resistance to allosteric mTOR inhibitors
}

\author{
Burhan Hassan ${ }^{1}$, Argun Akcakanat ${ }^{2}$, Takafumi Sangai ${ }^{1}$, Kurt W. Evans², Farrell \\ Adkins $^{1}$, Agda Karina Eterovic ${ }^{3}$, Hao $\mathrm{ZhaO}^{4}$, Ken Chen ${ }^{4}$, Huiqin Chen ${ }^{5}$, Kim-Anh \\ Do $^{5}$, Shelly M. Xie ${ }^{1}$, Ashley M. Holder ${ }^{1}$, Aung Naing ${ }^{2}$, Gordon B. Mills ${ }^{3}$ and Funda \\ Meric-Bernstam ${ }^{1,2}$ \\ 1 Department of Surgical Oncology, The University of Texas MD Anderson Cancer Center, Houston, TX \\ 2 Department of Investigational Cancer Therapeutics, The University of Texas MD Anderson Cancer Center, Houston, TX \\ ${ }^{3}$ Department of Systems Biology, The University of Texas MD Anderson Cancer Center, Houston, TX \\ ${ }^{4}$ Department of Bioinformatics and Computational Biology, The University of Texas MD Anderson Cancer Center, Houston, TX \\ ${ }^{5}$ Department of Biostatistics, The University of Texas MD Anderson Cancer Center, Houston, TX \\ Correspondence to: Funda Meric-Bernstam, email: fmeric@mdanderson.org \\ Keywords: mTOR, Akt, rapamycin, everolimus, breast cancer
}

Received: June 10, $2014 \quad$ Accepted: August 09, 2014

Published: August 10, 2014

This is an open-access article distributed under the terms of the Creative Commons Attribution License, which permits unrestricted use, distribution, and reproduction in any medium, provided the original author and source are credited.

\section{ABSTRACT}

We tested the antitumor efficacy of mTOR catalytic site inhibitor MLN0128 in models with intrinsic or acquired rapamycin-resistance. Cell lines that were intrinsically rapamycin-resistant as well as those that were intrinsically rapamycinsensitive were sensitive to MLN0128 in vitro. MLN0128 inhibited both mTORC1 and mTORC2 signaling, with more robust inhibition of downstream 4E-BP1 phosphorylation and cap-dependent translation compared to rapamycin in vitro. Rapamycin-sensitive $B T 474$ cell line acquired rapamycin resistance (BT474 RR) with prolonged rapamycin treatment in vitro. This cell line acquired an mTOR mutation (S2035F) in the FKBP12rapamycin binding domain; $\mathrm{mTORC1}$ signaling was not inhibited by rapalogs but was inhibited by MLN0128. In BT474 RR cells, MLN0128 had significantly higher growth inhibition compared to rapamycin in vitro and in vivo. Our results demonstrate that MLN0128 may be effective in tumors with intrinsic as well as acquired rapalog resistance. $\mathrm{mTOR}$ mutations are a mechanism of acquired resistance in vitro; the clinical relevance of this observation needs to be further evaluated.

\section{INTRODUCTION}

The Phosphatidylinositol 3-kinase (PI3K)/Akt/ mammalian target of rapamycin (mTOR) pathway plays a central role in cell metabolism, growth, proliferation and, survival $[1,2]$. Activation of PI3K/Akt/mTOR signaling contributes to the pathogenesis of many tumor types, and thus the pathway is being actively pursued as a promising therapeutic target [3-5]. mTOR, an important component of this pathway, exists in two multiprotein complexes: mTOR complex 1 and mTOR complex 2 (mTORC1 and $\mathrm{mTORC} 2$ ). mTORC1 includes the mTOR protein, mammalian LST8, proline rich Akt substrate 40 (PRAS40) and raptor $[1,6,7]$ and controls cell growth, survival, angiogenesis and protein translation via its two major substrates S6 kinase (S6K) and 4E-BP1 [8, 9]. Activated S6K causes feedback inhibition of insulin-like growth factor-1 (IGF-1)/insulin signaling by phosphorylating insulin receptor substrate 1 (IRS-1) resulting in its degradation [10]. mTORC2 consists of mTOR, mLST8, mSIN1, protor and rictor [11-15]. It has been shown that mTORC2 phosphorylates Akt at Serine 473 (S473), enhancing the catalytic activity of Akt, that has already been phosphorylated at Threonine 308 (T308) [16, 17]. Thus, the mTOR complexes play an important role both upstream and downstream of Akt [18].

Rapamycin and its analogs are allosteric mTOR inhibitors that bind FKBP12 and mTOR, and predominantly inhibit mTORC1. The rapamycin 
analog temsirolimus is approved by the Food and Drug Administration for the treatment of advanced renal cell carcinoma and the rapamycin analog everolimus is FDA approved for the treatment of pancreatic neuroendocrine tumors, renal cell carcinoma, sub-ependymal giant cell astrocytoma associated with tuberous sclerosis, as single agent therapy, and for the treatment of hormonereceptor positive breast cancer as combination therapy with exemestane. Rapalogs have also shown promise in clinical trials in other tumor types, such as mesothelioma and endometrial cancer $[1,19]$. However, rapalogs have shown objective responses in only a subset of patients, and unfortunately the responses are frequently shortlived. Mechanisms of acquired resistance to rapalogs are unknown.

These therapeutic failures have been attributed, in part, to rapamycin-induced Akt activation, as a result of inhibition of the S6K/IRS-1 feedback loop. Rapamycin not only inhibits S6K phosphorylation but also induces Akt S473 phosphorylation, hence activating Akt [20, 21]. Although we have observed that rapamycin-induced Akt phosphorylation is increased more in rapamycinsensitive cell lines compared to resistant cell lines [3], rapamycin-mediated Akt activation may be responsible for the attenuated antitumor efficacy of rapamycin and its analogs observed in patients. Approaches to prevent Akt activation, such as the use of inhibitors of upstream signaling, are being pursued [22]. However, an alternate approach is to target this pathway with mTOR kinase inhibitors that potently inhibit mTORC1 as well as mTORC2, thus inhibiting Akt S473 phosphorylation, and thereby preventing or attenuating the feedback loop activation of Akt and potentially treating PI3K/mTOR dependent cancers more effectively [23].

MLN0128, also known as INK128, is a novel ATPcompetitive mTOR kinase inhibitor, currently in phase I clinical trials for advanced solid malignancies. We sought to determine the effect of MLN0128 on rapamycin sensitive cell lines as well as in cell lines with intrinsic and acquired rapamycin-resistance both in vitro and in vivo. We demonstrate that MLN0128 caused greater inhibition of mTORC1 signaling, mTORC2 signaling, cell cycle progression and translation in most cell lines compared to rapamycin. Likewise, MLN0128 sensitivity was significantly greater in cell lines that have either intrinsic resistance to rapamycin or have acquired rapamycin resistance highlighting the efficacy of this compound in resistant settings compared to rapamycin. Furthermore, MLN0128 caused growth inhibitory effect in several in vivo models, and had a greater growth-inhibitory effect in in vivo models of acquired rapamycin resistance. Further, we report that prolonged rapamycin treatment in vitro was associated with acquisition of an mTOR kinase mutation, with insensitivity to rapamycin-mediated inhibition of mTOR signaling and cell growth, but with sensitivity to MLN0128.

\section{RESULTS}

\section{MLN0128 has Potent Antitumor Efficacy In Vitro}

We tested the MLN0128 sensitivity of 16 cell lines; the panel was enriched for breast cancer cell lines but consisted of cell lines with varying genomic alterations including mutations in PIK3CA and PTEN. These cell lines were selected as they represented cell lines with a range of sensitivities to rapamycin based on our previous study of a larger 43 cell line screen for rapamycin sensitivity (Supplementary Table S1) [3]. MLN0128 and rapamycin sensitivity was assessed by sulforhodamine B (SRB) assay (Fig. 1A). As expected the sensitivity of cell lines to rapamycin varied [3]. Most cell lines were sensitive to MLN0128 with IC50s in the low nano-molar range. T47D and ZR75-1 cell lines were sensitive to both MLN0128 and rapamycin. MDA-MB-231, ACHN, and A498 cell lines were resistant to rapamycin but sensitive to MLN0128. HT29 and HeLa cell lines were resistant to rapamycin, and were less sensitive to MLN0128, but still had significant growth inhibition with clinically achievable MLN0128 concentrations (HT29 IC50 $=150 \mathrm{nM}$ and HeLa IC $50=75 \mathrm{nM}$ ).

The effect of MLN0128 on cell cycle progression was analyzed by flow cytometry (Fig. 1B). Cancer cell lines were treated with vehicle, rapamycin $100 \mathrm{nM}$, or MLN0128 $100 \mathrm{nM}$ for 3 days, and percentages of cells in subG1, G1, S, and $\mathrm{G} 2 / \mathrm{M}$ phases were measured. Both MLN0128 $(P<0.0001)$ and rapamycin $(P<0.01)$ caused significant inhibition of cell cycle progression from G1 to S phase in T47D. In MDA-MB-231 and HT29, MLN0128, but not rapamycin, significantly increased the percentage of cells in G1 phase $(P<0.001)$. In ZR75-1 cell lines neither treatment increased cells in G1 phase; however, MLN0128 caused a significant increase in the subG1 population of cells $(P<0.001)$.

To determine whether MLN0128 induced apoptosis, cancer cell lines representative of each group were treated with vehicle or rapamycin $100 \mathrm{nM}$ or MLN0128 $100 \mathrm{nM}$ for 3 days, and the percentages of annexin $\mathrm{V}$ positive cells were determined (Supplementary Fig. S1A). MLN0128 induced significant apoptosis $(P<0.0001)$ in ZR75-1 cells only, corresponding with an increase in the subG1 population of cells observed in cell cycle analysis. We did not see significant apoptosis in other cell lines. Immunoblotting also showed no increase in expression of cleaved caspase 3 or cleaved PARP with MLN0128 treatment (Supplementary Fig. S1B).

We also assessed the effect of MLN0128 and rapamycin on anchorage-dependent growth of T47D, MDA-MB-231, HeLa and HT29 cells using a colony formation assay. Two weeks later, cell colonies were stained with crystal violet, plates were scanned and the 
colonies quantitated. MLN0128 treatment resulted in a dramatic decline in colony-forming ability compared with rapamycin treatment (Fig. $1 \mathrm{C}$ and D).

Hence, MLN0128 was found to have growth inhibitory in several cancer cell lines with differing genomic backgrounds and with varying rapamycin sensitivity. However, MLN0128 predominantly had a cytostatic effect with little effect on apoptosis and or autophagy in most cell lines tested.

\section{MLN0128 Inhibits mTORC1 and mTORC2 Signaling}

mTOR kinase inhibitors have been shown to inhibit mTORC1 and mTORC2 [24, 25]. The effects of MLN0128 and rapamycin on $\mathrm{mTORC} 1$ and $\mathrm{mTORC} 2$ signaling were compared in rapamycin sensitive and resistant cell lines groups (Fig. 2A). Rapamycin potently inhibited the phosphorylation of S6, downstream substrate of mTORC1,

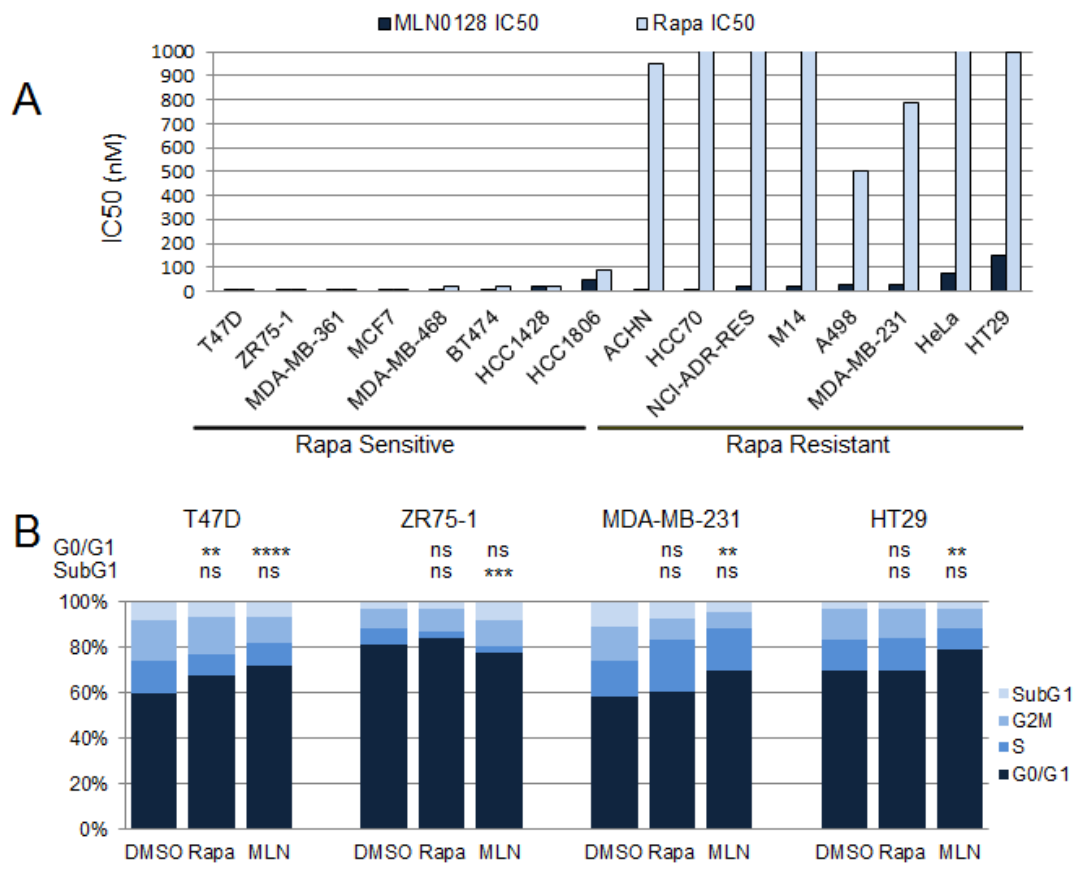

C
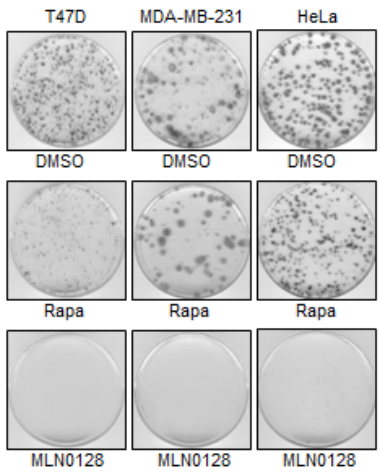

D

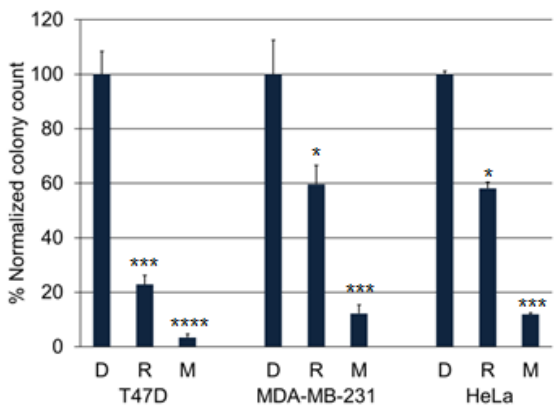

Figure 1: MLN0128 has potent antitumor efficacy in vitro. (A) Sixteen cell lines with varying genetic backgrounds were treated with increasing doses of MLN0128 and rapamycin with IC50 being determined by SRB assay. (B) Cancer cell lines were treated with vehicle, rapamycin (100 nM), or MLN0128 (100 nM) in triplicate for 96 hours, and percentages of cells in G1 (navy), S (royal blue), G2/M (blue), and SubG1 (light blue) phases of the cell cycle were determined by flow cytometry. The percentages of cells in G1 or subG1 phases in each treatment group were compared ( $* * P<0.01, * * * P<0.001, * * * * P<0.0001$, ns not significant, vs. control). This experiment was repeated three times and the results of one representative experiment done in triplicates are shown. (C) Effect of MLN0128 treatment on anchorage-dependent growth. T47D, MDA-MB-231, and HeLa cells were trypsinized, counted and plated at a density of $0.5-1 \times 10^{3}$ cells/60 mm plates in triplicate for each treatment group. Cells were treated with vehicle, rapamycin (100 nM), or MLN0128 (100 nM) in triplicate for 2-3 weeks, colonies were then stained with crystal violet. (D) Individual colonies were counted using NIH ImageJ v.1.46 software. The colonies in each treatment group were normalized and compared. Data are presented as mean $\pm \mathrm{SE}(* P<0.05$, $* * * P<0.001$, $* * * * P<0.0001$, vs. control). This experiment was repeated three times and the results of one representative experiment done in triplicates are shown. 
but poorly inhibited 4E-BP1 phosphorylation as has been previously described [26, 27]. In contrast MLN0128 effectively inhibited S6 and 4E-BP1 phosphorylation, hence showing strong $\mathrm{mTORC} 1$ inhibition compared with rapamycin.

As has been reported previously, rapamycin did not inhibit mTORC2 and in certain contexts, induced Akt S473 phosphorylation [20, 21]. On the contrary, MLN0128 inhibits phosphorylation of Akt at S473, a downstream substrate of mTORC2 (Fig. 2A). Hence MLN0128 inhibited mTORC2, preventing mTORC2dependent feedback activation of Akt; however, MLN0128 did increase phosphorylation of Akt at T308 in T47D, ZR75-1, and A498 cells (Fig. 2A).

\section{MLN0128 Decreases Cap-dependent and Cap- independent Translational Activity}

To determine the effect of MLN0128 on protein translation, a reporter plasmid construct pCDNA3-rLucpolIRES-fLUC was used that once transfected measures cap-dependent translational activity through renilla luciferase activity and internal ribosomal entry system (IRES) dependent translation through firefly luciferase activity. T47D (intrinsically sensitive to rapamycin) and MDA-MB-231 cells (intrinsically resistant to rapamycin), were transfected with reporter plasmid and a dual luciferase assay kit was used to measure renilla and firefly activity (Fig. 2B). In both cell lines, MLN0128 treatment decreased cap-dependent translation.

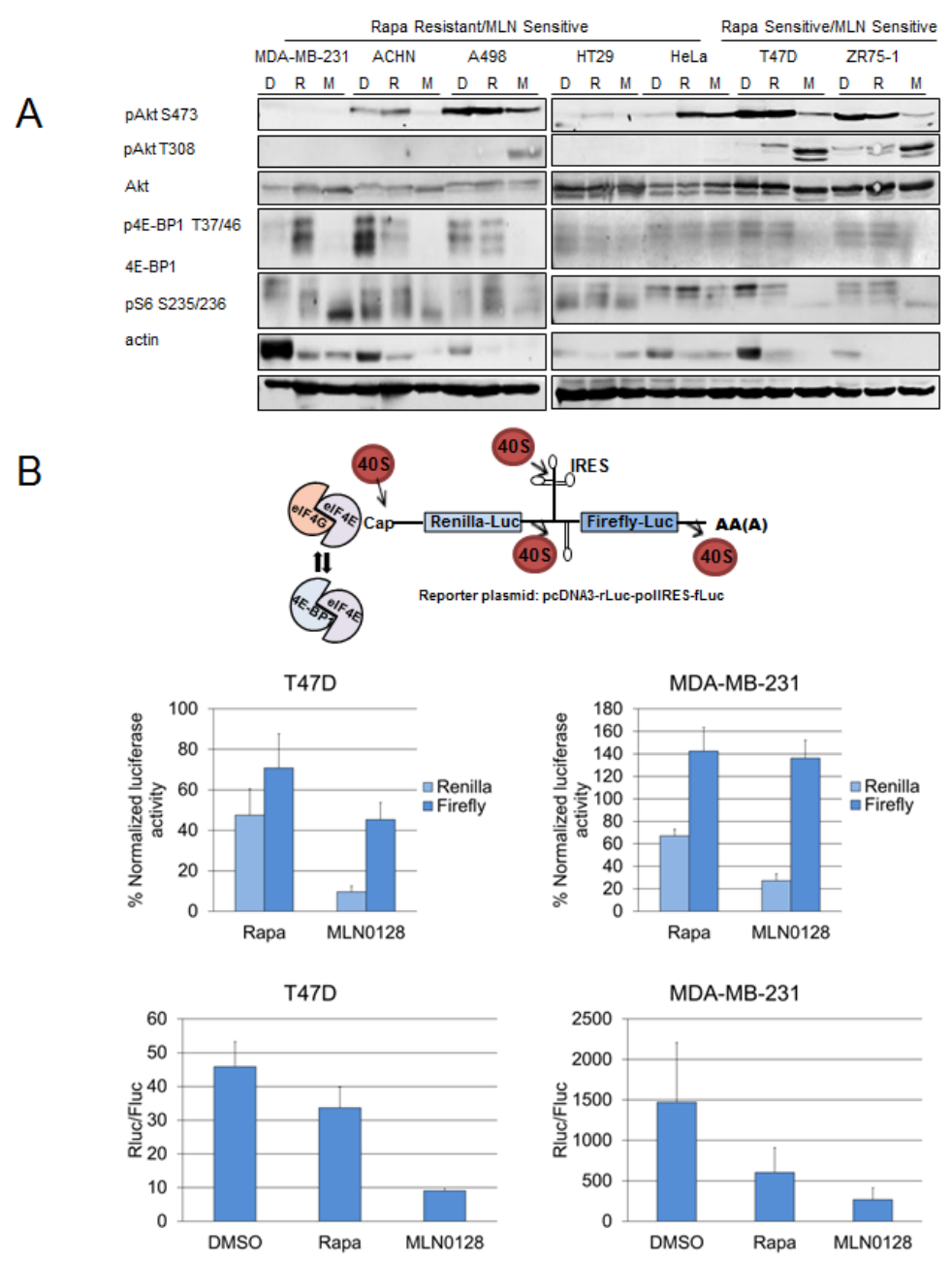

Figure 2: MLN0128 inhibits mTORC1 and mTORC2 signaling. (A) MDA-MB-231, ACHN, A498, HT29, HeLa, T47D, and ZR75-1 cell lines were treated daily with vehicle, rapamycin $(100 \mathrm{nM})$, and MLN0128 (100 nM) for 72 hours. Western blotting was performed to assess mTORC1 and mTORC2 signaling. (B) MLN0128 decreases translational activity. Cancer cell lines T47D and MDAMB-231 were trypsinized, counted, and plated on $60 \mathrm{~mm}$ plates. They were transfected with a bicistronic pcDNA3-rLuc-polIRES-fLUC plasmid (construct detailed in the figure, where Renilla-Luc measures cap-dependent activity and Firefly-Luc measures cap-independent activity) and then treated with vehicle, rapamycin (100 nM), and MLN0128 (100 nM) for 24 hours. Dual luciferase assay kit was used to measure luciferase activity. The data represent the mean $\pm \mathrm{SE}$ of three independent experiments performed in triplicate and analyzed $(* * P<0.01, * * * P<0.001$, vs. control). 


\section{MLN0128 Causes Growth Inhibition In Vivo}

To expand our findings in vivo, we determined the activity of MLN0128 in five different xenograft models. We analyzed xenografts from ZR75-1, MCF7 cell lines that are rapamycin-sensitive in vitro and xenografts from ACHN, MDA-MB-231 and HT29 cell lines that are rapamycin-resistant in vitro. The statistical analyses were done by comparing tumor volumes in treatment arms with tumor volumes in the vehicle arm at the termination of experiment. Mice bearing ACHN, ZR751 or MDA-MB-231 xenografts did not show statistically significant growth inhibition with everolimus treatment
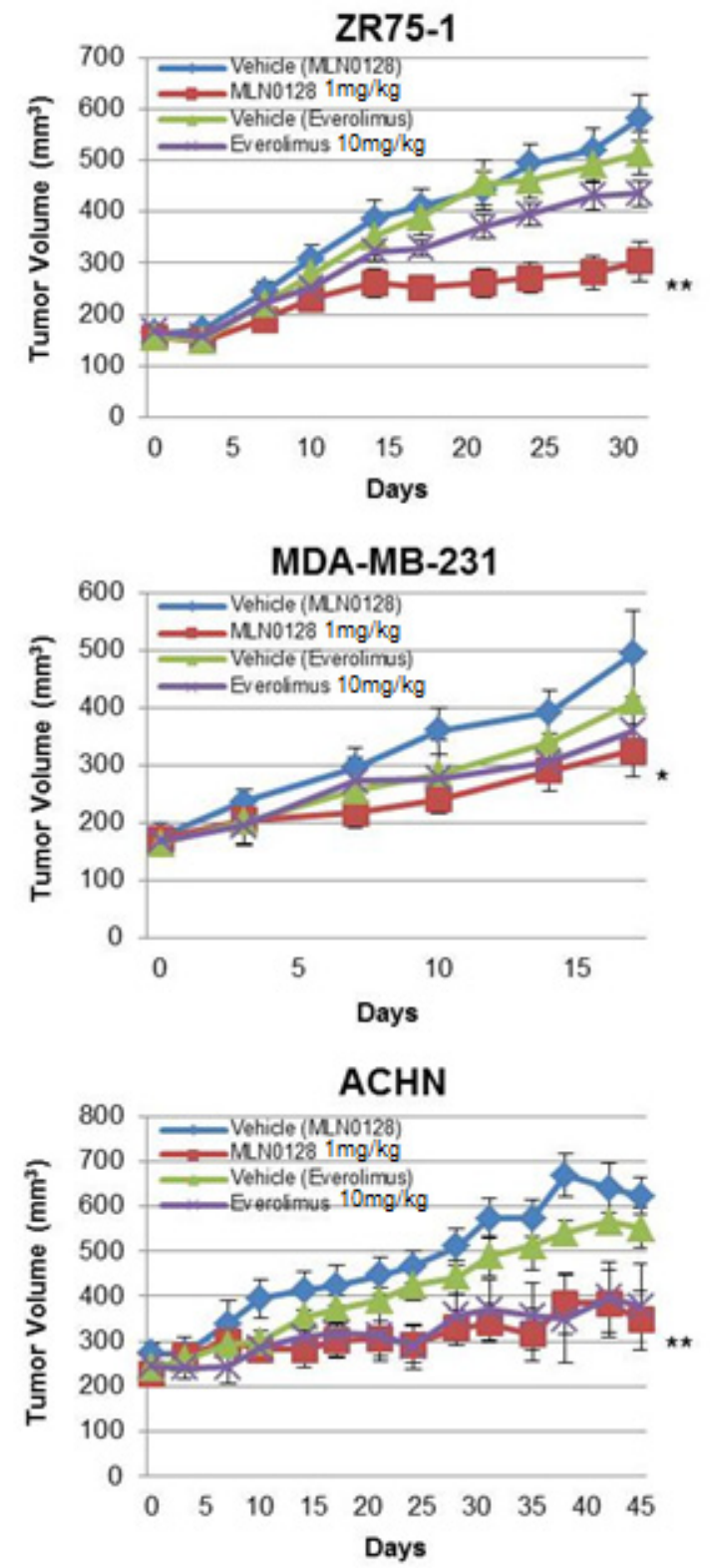

( $P=0.1792, P=0.0591$, and $P=0.8541$ respectively) (Fig. 3). In contrast, MLN0128 treatment, at doses of $1 \mathrm{mg} / \mathrm{kg}$, previously described as an in vivo effective dose [28-31], led to significant tumor growth inhibition was observed compared with vehicle in all three cell lines $(\mathrm{ACHN}$ $P=0.0093$, ZR75-1 $P=0.0012$, MDA-MB-231 $P=0.0263$ ). In MCF7 xenografts, both MLN0128 and everolimus caused significant growth inhibition $(P=0.0012$ and $P=0.0022$, respectively). In contrast, HT29 xenografts responded to everolimus resulting in significantly lower tumor volume $(P=0.0072)$ but with MLN0128 treatment, a decrease in tumor volume was observed but was not statistically significant $(P=0.0827)$.
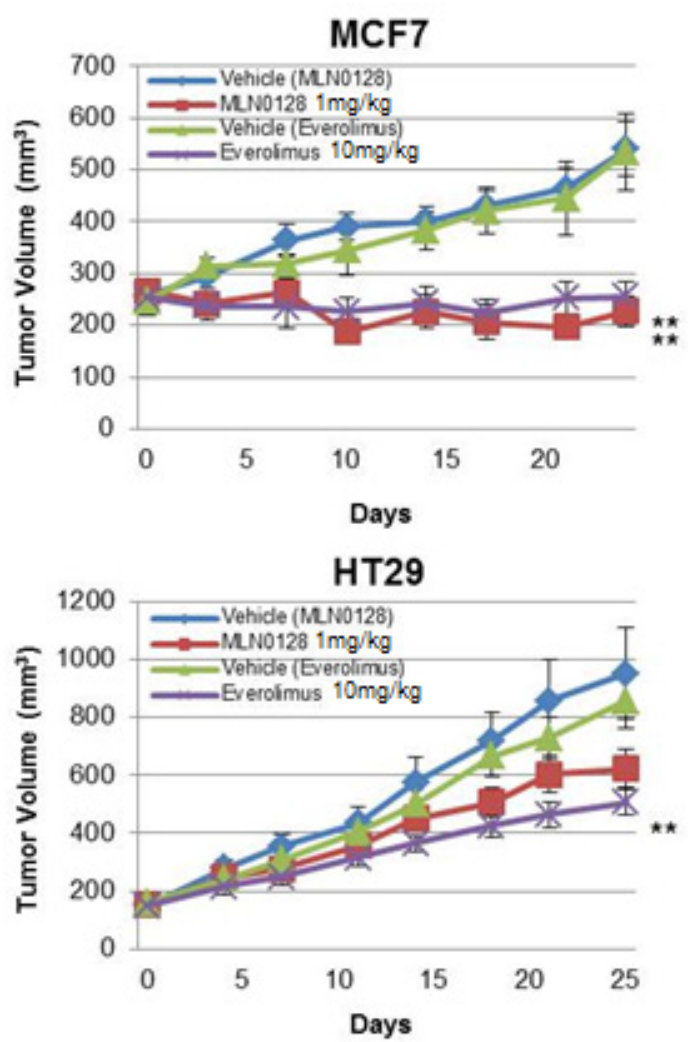

Figure 3: MLN0128 has in vivo antitumor efficacy. Mice bearing ZR75-1, MCF7, MDA-MB-231, HT29, and ACHN xenografts were treated with vehicle, everolimus $10 \mathrm{mg} / \mathrm{kg}$, and MLN0128 $1 \mathrm{mg} / \mathrm{kg}$. The tumor volumes at the conclusion of experiment were compared to vehicle and data was analyzed by Mann-Whitney U test. Data are presented as mean $\pm \operatorname{SE}(* P<0.05, * * P<0.01$, vs. control). 


\section{MLN0128 is Effective in Cell Lines with Acquired Resistance to Rapamycin}

Although rapalogs often have antitumor efficacy of limited duration in the clinic, currently little is known about mechanisms of acquired resistance to rapalogs. To get insight into mechanisms of acquired rapamycin resistance and approaches to overcome them, we created BT474 rapamycin resistant (BT474 RR) cell lines through culturing rapamycin-sensitive BT474 parental cells (BT474 Par) in progressively higher concentrations of rapamycin. We then tested the activity of MLN0128 in BT474 Par and RR cell lines in vitro.

BT474 Par cell lines were sensitive to the growthinhibitory effect of rapamycin and everolimus, and at clinically relevant levels, MLN0128 as well as, rapalogs, inhibited BT474 Par. In contrast neither rapamycin nor everolimus significantly inhibited BT474 RR cell line growth while MLN0128 demonstrated significant growth inhibitory effect on BT474 RR cells in vitro (Fig. 4A).

As expected in BT474 Par cells, immunoblotting showed that rapamycin inhibited mTORC1 substrates (p4E-BP1, pS6K) and downstream pS6, with activation of pAkt S473, while MLN0128 treatment inhibited pAkt S473 and inhibited p4E-BP1 more robustly (Fig. 4B). Strikingly in BT474 RR cell lines neither rapamycin nor everolimus inhibited the mTORC1 axis i.e. pS6, pS6K T389, or p4E-BP1. In contrast MLN0128 robustly inhibited mTORC1 signaling (Fig. 4A).

The effect of rapamycin and MLN0128 was then assessed on cap-dependent and independent translation. BT474 Par and BT474 RR cells were transfected with the bicistronic luciferase vector (as in Fig. 2B) and treated with rapamycin or MLN0128. In BT474 Par and BT474 RR cell lines, only MLN0128 caused statistically significant decline in both cap-dependent (both cell lines, $P<0.001$ )

Figure 4: MLN0128 is effective in cell lines with acquired rapamycin resistance. (A) BT474 Par and RR cell lines were treated with increasing doses of MLN0128, everolimus and rapamycin, using SRB assay to determine IC50. These experiments were repeated at least three times and data are presented as mean \pm SE. (B) These cell lines were treated daily with vehicle, rapamycin (100 nM), and MLN0128 (100 $\mathrm{nM})$ for 72 hours. Western blotting was performed to assess mTORC1 and mTORC2 signaling. (C) Cancer cell lines BT474 Par, and BT474 RR were trypsinized, counted and plated on 60 $\mathrm{mm}$ plates. They were transfected with pcDNA3-rLuc-polIRESfLUC plasmid then treated with vehicle, rapamycin $(100 \mathrm{nM})$, and MLN0128 (100 nM) for 24 hours. Dual luciferase assay kit was used to measure luciferase activity. The data represent mean \pm SE of three independent experiments performed in triplicate and analyzed $\left(* * P<0.01,{ }^{*} * * P<0.001\right.$, vs. control). (D) BT474 Par and RR cell lines were treated daily with vehicle, rapamycin $(100 \mathrm{nM})$, or MLN0128 (100 nM) for 72 hours. Relative levels of cap-bound 4E-BP1 and eIF4G were compared using western blotting. and cap-independent (BT474 Par, $P<0.01$; BT474 RR, $P<0.001)$ translational activity while rapamycin decreased cap-dependent $(P<0.001)$ translational activity in BT474 Par cell lines only (Fig. 4C).

Phosphorylation of 4E-BP1 by mTORC1 leads to its dissociation from eIF4E, allowing binding of eIF4G at the same site, hence allowing translation initiation complex formation at the 5 ${ }^{`}$ end of mRNAs [27]. Thus, we expected that MLN0128 by de-phosphorylating 4E-BP1 leads to a decrease in translational activity, decreasing eIF4G-eIF4E binding. BT474 Par and BT474 RR cell lines were treated with control, rapamycin and MLN0128. The fraction of eIF4E associated with 4E-BP1 and eIF4G was examined by purification of lysates using 7-methyl GTP-sepharose beads; eIF4E and eIF4E-bound proteins were detected by immunoblotting analysis. Rapamycin led to a decrease in eIF4E-associated eIF4G in BT474 Par cells but not BT474 RR cells (Fig. 4D). In contrast, MLN0128 resulted in a

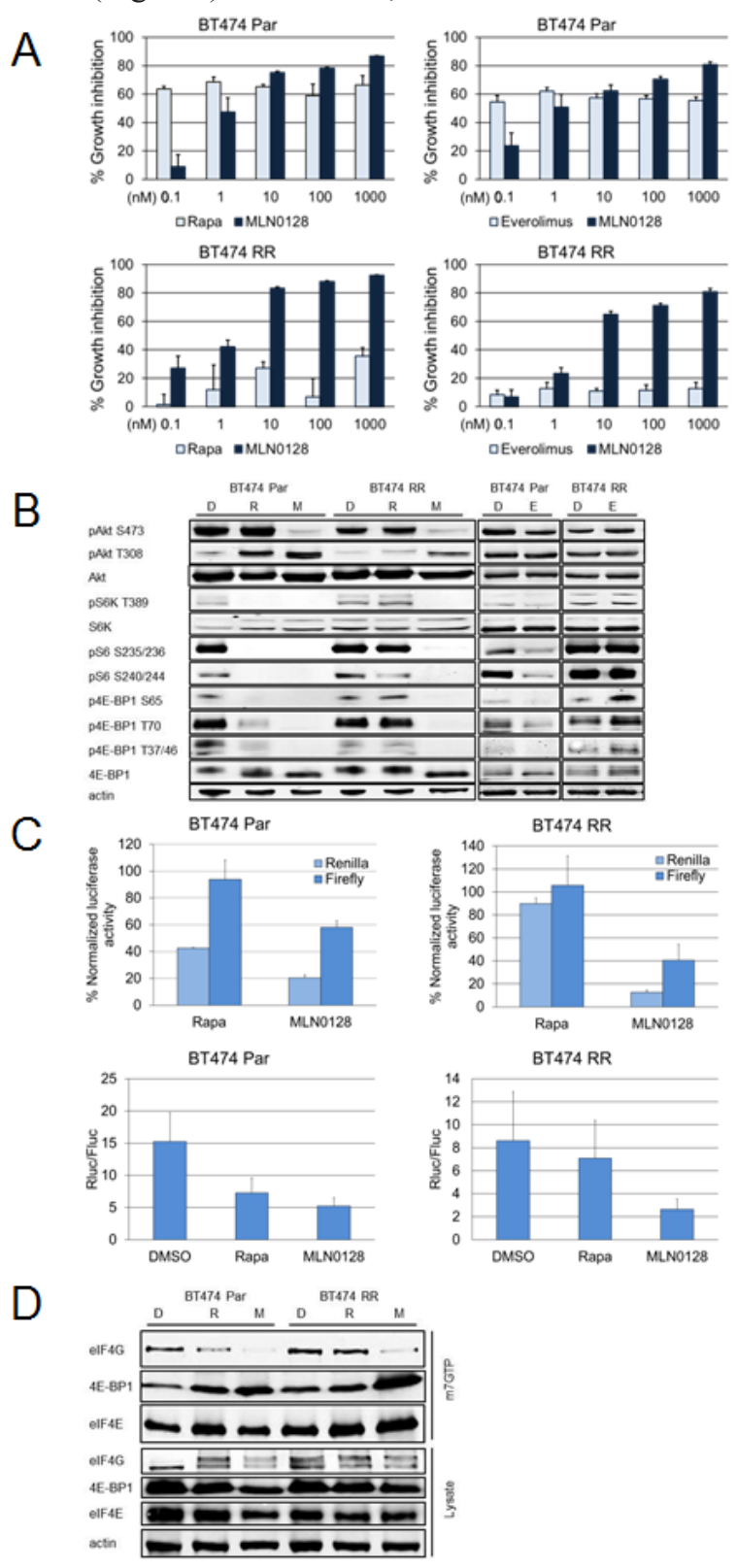


decrease in eIF4G associated with eIF4E in both BT474 Par cells and BT474 RR cells.

\section{Rapamycin Resistant BT474 RR cells Harbor an mTOR Mutation}

As rapamycin did not inhibit mTORC1 signaling in BT474 RR cells, we hypothesized that prolonged rapamycin treatment may have caused an acquired mutation in mTOR or other upstream kinases with constitutive activation of mTORC1 signaling. To test this hypothesis, we performed targeted exome sequencing cells using a 202 gene panel that includes mTOR as well as multiple other cancer-related genes (Supplementary Table S2). Comparing BT474 Par and BT474 RR cells, we identified an mTOR S2035F mutation in the BT474 RR cells (Fig. 5A). This mutation corresponds to the FKBP12-rapamycin binding domain of mTOR and has been previously described in vitro transcription and translation assays, and in yeast models as a mutation known to interfere with mTOR-FKBP12 interaction and to confer rapamycin-resistance [32-34]. The existence of this point mutation was confirmed with digital polymerase chain reaction (Fig. 5B and 5C).

\section{Acquired Rapamycin-Resistant Cell Lines are Sensitive to MLN0128 in vivo}

Next, we determined the in vivo effect of rapamycin and MLN0128 in BT474 PAR and RR xenograft models. In the BT474 Par xenografts, both rapamycin and MLN0128 treatment showed significant tumor growth inhibition (for all treatment groups, $P<0.05$ ) compared to vehicle (Fig. 6A and 6B). In the BT474 RR xenograft model, rapamycin treatment did not lead to significant tumor growth inhibition; however, MLN0128 treatment resulted in significant tumor growth inhibition $(P=0.0152)$ in comparison with vehicle.

\section{DISCUSSION}

Akt/mTOR signaling plays key roles in controlling major cellular processes, including cell growth, protein translation, autophagy, metabolism, and cell survival $[1,2]$. Activated Akt/mTOR signaling is a significant contributor to pathogenesis of cancer. Akt and mTOR have been shown to reciprocally regulate activity [25]. MLN0128 is an ATP-competitive mTOR kinase inhibitor; we sought to determine the antitumor efficacy of MLN0128 in cell lines of varying genetic backgrounds

A

\begin{tabular}{|c|c|c|c|c|c|c|c|c|c|}
\hline HGNC & AlleleFreq & Coverage & UploadedVariation & CDS Position & Protein Position & Codons & Consequence & Condel & PolyPhen \\
\hline MTOR & $31.10 \%$ & 1013 & $1 \_11187793$ C $/ T$ & 6104 & S2035F & tCt/tTt & nonsynonymous & $\begin{array}{c}\text { Deleterious } \\
(0.911)\end{array}$ & $\begin{array}{c}\text { Probably } \\
\text { damaging(0.997) }\end{array}$ \\
\hline
\end{tabular}

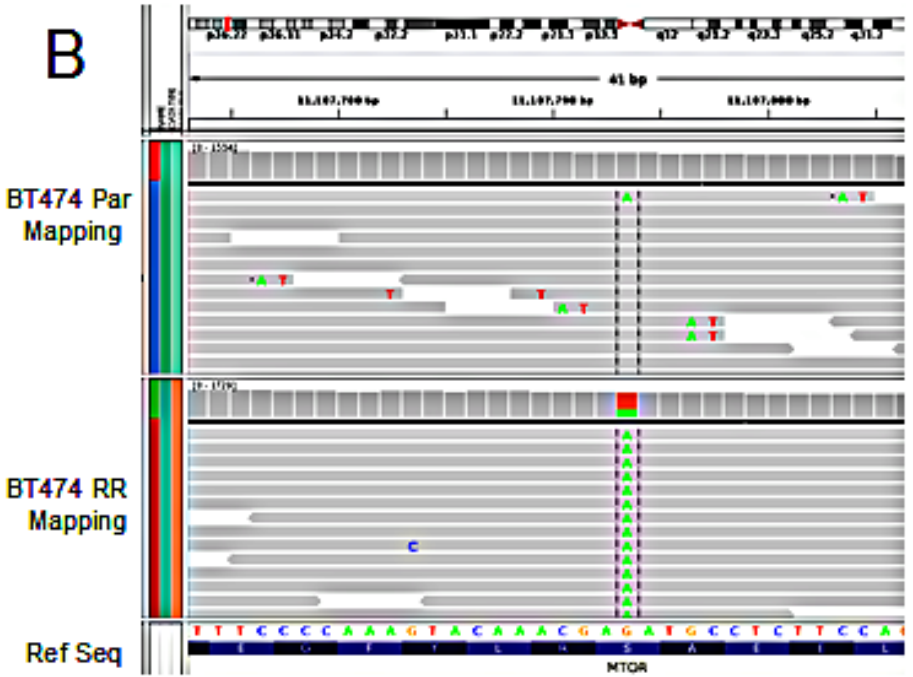

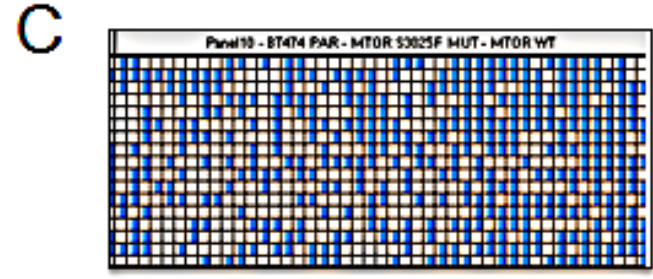

BT474 Par 1000

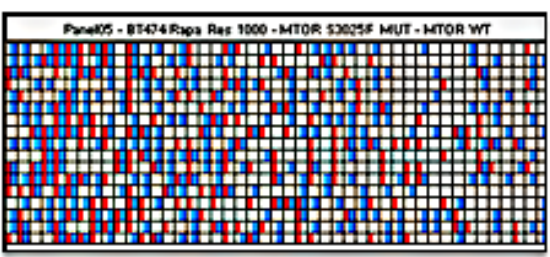

BT474 RR 1000

Figure 5: BT474 RR harbors an acquired mTOR mutation. (A) Next-generation sequencing identified a mutation at mTOR S2035F in the resistant cell lines. (B) and (C) Heatmap view generated by the Biomark digital PCR analysis software for confirmation of mutation at mTOR S2035F. The panel shown here represents two samples: BT474 Par and BT474 RR 1000 copy/panel samples. The red spot highlights mutation. 
and varying sensitivity to rapamycin. We demonstrated that MLN0128 potently inhibits both S6 and 4E-BP1 phosphorylation in cells, with more robust inhibition of mTORC1 signaling than rapamycin; also in addition, MLN0128 completely inhibits the phosphorylation of Akt S473, consistent with its efficient inhibition of mTORC2 as well.

Rapamycin analogs have been FDA-approved for treatment of several tumor types, but single agent treatment has resulted in modest objective response rates. Where there is activity observed with allosteric mTOR inhibitors, they appear to be cytostatic, primarily stabilizing clinical disease, rather than resulting in tumor regression [1]. mTORC1 is implicated in several human diseases, such as diabetes, heart disease, obesity, and cancer. These diseases reveal aberrant cell growth and proliferation. Unlike S6Ks, 4E-BPs do not have an effect on cell size, but they regulate proteins involved in cell proliferation and cell cycle progression [35]. By evolving resistance to $\mathrm{mTOR}$ inhibitors, several studies identified a decrease in 4E-BP expression and an increase in expression of eIF4E and c-Myc [36-38]. Further, the 4E$\mathrm{BP} / \mathrm{eIF} 4 \mathrm{E}$ ratio was suggested as an indicator of acquired and intrinsic resistance [36]. In BT474 Par cells, we observed a partial inhibition of phosphorylation of 4E-BP1 by rapamycin and everolimus, whereas in BT474 RR cells

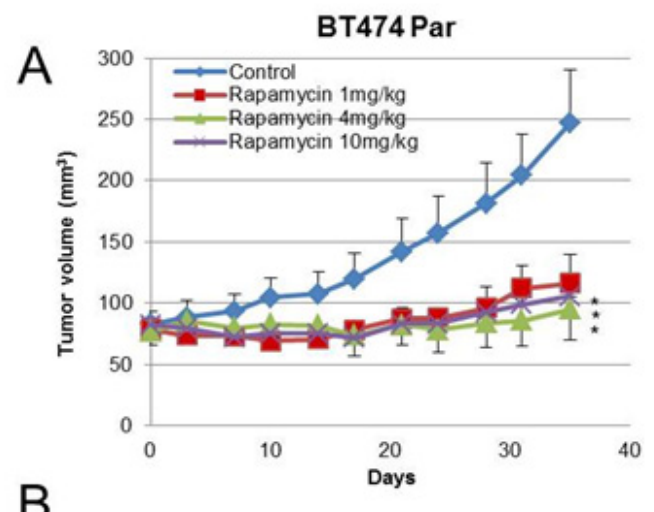

B

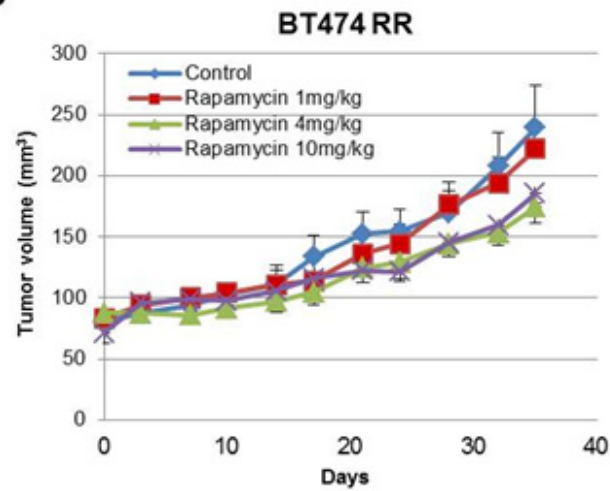

there was no inhibition. In contrast, MLN0128 inhibited 4E-BP1 phosphorylation in both cell lines completely. Considering the recently acknowledged importance of $\mathrm{mTOR} / 4 \mathrm{E}-\mathrm{BP}$ axis in rapamycin resistance, MLN0128 is likely to overcome this problem.

It has been proposed that this may be due to upregulation of feedback loops in which Akt phosphorylation and activity are increased by relieving S6K-driven suppression of IGF-1R signaling [21]. Some studies suggest that inhibition of mTORC2 will lead to the dephosphorylation of Akt at the S473 site and a more profound inhibition of Akt function than would be expected from dephosphorylation of Akt T308 alone [24, 39]. Thus, mTOR kinase inhibition has been proposed to prevent the feedback loop activation of Akt that may attenuate the response of patients with rapamycin therapy. In our data, MLN0128 showed potent and persistent mTORC1 and mTORC2 inhibition; however the inhibition of phosphorylation of Akt T308 is only temporary. These results are consistent with other work that demonstrated a biphasic Akt inhibition with mTOR kinase inhibitor AZD8055 [40]. This induction of PI3K activation may be due to relief of feedback activation of RTK signaling. Despite reactivation of Akt T308, MLN0128 was effective in inhibiting cell growth, and protein translation in cell lines that are not only sensitive to rapamycin but
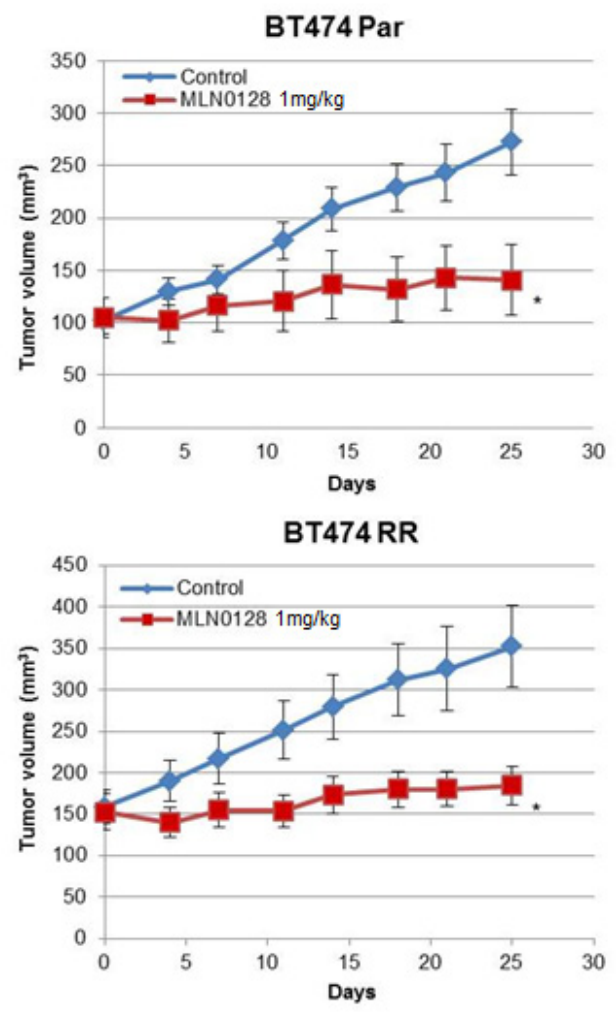

Figure 6: MLN0128 inhibits in vivo growth of rapamycin resistant BT474 RR cells. (A) Mice bearing BT474 Par xenografts were treated with vehicle, rapamycin $1 \mathrm{mg} / \mathrm{kg}, 4 \mathrm{mg} / \mathrm{kg}, 10 \mathrm{mg} / \mathrm{kg}$, or MLN0128 $1 \mathrm{mg} / \mathrm{kg}$. (B) Mice bearing BT474 RR xenografts were treated with vehicle, rapamycin $1 \mathrm{mg} / \mathrm{kg}, 4 \mathrm{mg} / \mathrm{kg}, 10 \mathrm{mg} / \mathrm{kg}$, or MLN0128 $1 \mathrm{mg} / \mathrm{kg}$. Tumor volumes at the conclusion of the experiment were compared to vehicle, and data was analyzed by Mann-Whitney $U$ test Data are presented as mean $\pm \operatorname{SE}(* P<0.05)$. 
also in cell lines that are resistant to rapamycin. Most cell lines were sensitive to MLN0128 with an IC50 in nanomolar range in vitro. In vivo, MLN0128 resulted in significant growth inhibition in five of the xenograft models tested representing cell lines with a variety of genomic backgrounds (ZR75-1, MCF7, MDA-MB-231, BT474, ACHN, Supplementary Table S1). However, tumor regression was observed only in MCF7 xenografts emphasizing the need to pursue novel combinations, and raising the possibility that combinatorial therapies that also abrogate Akt T308 phosphorylation may have even greater in vivo tumor efficacy. We observed that some of our in vitro and in vivo results did not correlate completely. The growth of rapamycin-sensitive ZR75-1 xenografts was not significantly inhibited by everolimus. Similar discrepancies between in vitro and in vivo models are well-known. An in depth analysis of effect of everolimus on mTORC1 and mTORC2 activities may explain the mechanistic background of this discrepancy. Also, although HT29 cells were relatively resistant to rapamycin in vitro, the in vivo growth of HT29 xenografts was inhibited by everolimus ( $P=0.0072)$ but not by MLN0128 $(P=0.0827)$. It is feasible that a larger study may have indeed demonstrated a statistically significant difference with MLN0128 as well. The greater antitumor efficacy in vivo than in vitro suggests that xenograft models capture additional antitumor mechanisms of action. Indeed a recently study but Mercier et al. demonstrated mTOR inhibition with rapamycin can have multiple effects on the microenvironment including decreases in the levels of angiogenesis, collagen deposition, and the total number of fibroblasts in the tumor stroma [41].

Most patients who derive clinical benefit from rapalogs may have disease stabilization for several months but ultimately progress. [41-43] The mechanism of acquired resistance to rapamycin analogs remains unknown at this time. There is increasing recognition that tumors evolve with progression and with treatment pressure. A variety of acquired genomic alterations that confer resistance to targeted therapies have been described including acquired Bcr-Abl mutations in response to imatinib treatment [44], ras mutations with cetuximab [45], EGFR mutations [46, 47] MET amplification with EGFR inhibitors[48], and loss of HER2 with trastuzumabbased therapy [49]. Thus, an acquired mutation in mTOR is a logical mechanism for acquired rapamycin resistance. This precise mutation has not been reported in TCGA or COSMIC [50]. However, an extensive study of serine at 2035 showed that substituting with aspartate, threonine, glutamine, and isoleucine abolished FKBP12-rapamycin binding, whereas conversion to alanine had a similar binding affinity compared to wild-type [33]. Also, these mTOR S2035 mutants can phosphorylate S6K and 4EBP1 normally $[34,51,52]$. As there are no supporting experiments yet, it is not defined if the larger side chain of phenylalanine may abolish formation of complex or not.
Further studies are needed to determine if this alteration is acquired in patients treated with rapalogs. If so, for patients who initially had benefited from rapalogs may achieve additional benefit from transitioning to an mTOR kinase inhibitor or another PI3K/Akt/mTOR inhibitor.

In summary, MLN0128 is an effective inhibitor of mTORC1 and mTORC2 activity. Cancer cell lines with intrinsic as well as acquired resistance to rapamycin are responsive to mTOR kinase inhibitor MLN0128. Ongoing clinical trials will test the efficacy of MLN0128 in patients with intrinsic as well as acquired resistance. We also report the novel finding of an acquired mTOR mutation associated with acquired rapamycin resistance. Further studies are needed to clinically validate this finding.

\section{METHODS}

\section{Cell Lines and Cultures}

Cancer cell lines obtained from American Tissue Culture Collection were: A498, ACHN (kidney), BT474, HCC70, HCC1428, HCC1806, MCF7, MDA-MB-231, MDA-MB-361, MDA-MB-435, MDA-MB-453, MDAMB-468, T47D, ZR75-1 (breast), HeLa (cervix), HT29 (colon), and M14 (melanoma). NCI/ADR-RES ovarian cancer cells were obtained from the National Cancer Institute. All cell lines were maintained in DMEM/F12 media supplemented with $10 \%$ FBS and were passaged for less than 6 months after resuscitation and were authenticated by vendors.

\section{Acquired Resistance Cell Lines}

The breast cancer cell line BT474 was cultured in progressively increasing doses of rapamycin until sustained growth at supra-therapeutic $(10 \mu \mathrm{M})$ doses was achieved (approximately 18 months). Pool populations (non-clonal) of the parental cell lines (BT474 Par) and the cell lines with acquired rapamycin resistance (BT474 rapamycin resistant (RR)) were generated. Their identities were confirmed by short tandem repeat (STR) profiling.

\section{Reagents}

Rapamycin was purchased from LC Laboratories., Inc. DMSO was bought from Sigma-Aldrich. MLN0128 for in vitro studies was kindly provided by Intellikine Inc. (La Jolla, CA). Additional MLN0128 was purchased from ChemieTek (Indianapolis, IN). For in vivo experiments methyl cellulose, polyvinylpyrrolidone and N-methyl-2pyrrolidone (Sigma) were used as vehicles. 


\section{Cell Growth Assay}

Antiproliferative activity was tested by SRB assay [53]. The half maximal inhibitory concentration (IC50) was determined from dose-response curves after 4 days of treatment [54].

\section{Colony Formation Assay}

Colony formation assay was performed as previously described [55]. Briefly, cells were trypsinized, counted and plated at a density of 1-5 $\times 10^{3}$ cells depending on the cell lines $/ 60 \mathrm{~mm}$ plates in triplicate for each treatment group. Approximately 2-3 weeks later when the controls had colonies approaching confluency, plates were fixed, stained with crystal violet and scanned. The colonies were counted using NIH ImageJ v.1.46 software.

\section{Cell Cycle Analysis and Annexin V Binding Assay}

For cell cycle assay, floating cells, as well those that were attached to the culture dish, were collected. Samples were analyzed by flow cytometry and ModFit LT software (Verity Software House). Apoptosis was identified by using the Annexin V apoptosis kit (Roche) according to the manufacturer's protocol, and cells were analyzed by flow cytometry and FlowJo v.10 (Tree Star) [54].

\section{Western Blotting}

Immunoblotting was performed as described previously [56] with the following antibodies: Akt, pAkt T308, pAkt S473, caspase 3, eIF4E, eIF4G, LC3B, PARP, S6K, pS6K T389, pS6 S235/236, pS6 S240/244, 4E-BP1, p4E-BP1 T37/46, p4E-BP1 S65, p4E-BP1 T70 (Cell Signaling Technology, Inc.) and actin (Sigma).

\section{Dual Luciferase Assay}

The reporter plasmid pCDNA3-rLuc-polIRES-fLUC was a gift from Nahum Sonenberg. T47D, MDA-MB-231, BT474 Par and BT474 RR cell lines were transfected with reporter plasmid using DharmaFECT transfection reagent by Thermo Fisher Scientific, Inc. (Waltham, MA). Dual luciferase assays were performed with the dual luciferase reporter assay system (Promega Corp., Madison, WI) according to the manufacturer's protocol [57].

\section{eIF4E-containing 5' mRNA Cap Complex Analysis}

BT474 Par and RR cells were treated with DMSO, rapamycin $(100 \mathrm{nM})$ and MLN1028 $(100 \mathrm{nM})$ for 72 hours. Approximately $500 \mu \mathrm{g}$ of total protein for each condition was incubated with 7-methyl GTP Sepharose 4B beads (GE Healthcare, Piscataway, NJ) for two hours at $4^{\circ} \mathrm{C}$. Pelleted beads were washed twice with lysis buffer and suspended in 1X SDS-PAGE sample buffer (containing $12.5 \% \mathrm{v} / \mathrm{v} \beta$-mercaptoethanol) and eIF4E, eIF4G and 4E-BP1 levels contained in the elutes were analyzed by western blotting [58].

\section{Targeted Exome Sequencing}

Genomic DNA was extracted from BT474 Par and BT474 RR cell lines using Qiagen's Qiaprep Kit according to the manufacturer's protocol. DNA was quantified by Qubit (Invitrogen) and quality was assessed using Genomic DNA Tape for the 2200 TapeStation (Agilent). DNA was sheared by sonication and to ensure the proper fragment size, samples were checked on TapeStation using the DNA High Sensitivity kit (Agilent). The sheared DNA proceeded to library prep using KAPA library prep kit (KAPA) following the "with beads" manufacturer protocol. Samples were quantified using KAPA qPCR quantification kit. Equimolar amounts of DNA were pooled (8-12 samples per pool) for capture of 202 genes that are clinically relevant in cancer (Supplementary Table S2). We designed biotin labeled probes with Roche Nimblegen for capturing target regions (all exons in those 202 genes) and followed manufacture's protocol for the capture step. The captured libraries were sequenced on a HiSeq 2000 (Illumina Inc., San Diego, CA, USA) on a version 3 TruSeq paired end flowcell according to manufacturer's instructions at a cluster density between $700-1000 \mathrm{~K}$ clusters $/ \mathrm{mm} 2$. Sequencing was performed on a HiSeq 2000 for $2 \times 100$ paired end reads with a 7 nt read for indexes using Cycle Sequencing v3 reagents (Illumina). The resulting BCL files containing the sequence data were converted into ".fastq.gz" files and individual libraries within the samples were demultiplexed using CASAVA 1.8.2 with no mismatches. All regions were covered by $>20$ reads. For data analysis, the targetcaptured deep-sequencing data was aligned to human reference assembly hg19 using BWA and duplicated reads were removed using samtools. Single nucleotide variants (SNVs) and small indels were called using VarScan2 [59], which classified variants. To understand the potential functional consequence of detected variants, they were compared with dbSNP, COSMIC [50], and TCGA databases, and were annotated them using VEP [60], Annovar [61], SIFT [62], Polyphen [63], and Condel [64]. 


\section{Digital PCR}

Genomic DNA was extracted and quantified as above. Custom multiplexed genotyping qPCR assays capable of distinguishing the wild type and mutant alleles of mTOR were designed by and ordered from Life Technologies. Following the manufacturer's (Fluidigm) protocol, $3.5 \mathrm{ng}$ DNA was loaded on to a 12.75 Digital Array IFC chip and processed on the Fluidigm BioMark HD instrument. Data analysis was performed using Fluidigm's Digital PCR Analysis software.

\section{In Vivo Studies}

All animal experiments were approved by the MD Anderson Animal Care and Use Committee. BT474 Par

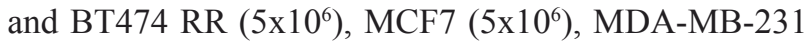
$\left(2 \times 10^{6}\right)$, and ZR75-1 $\left(1 \times 10^{7}\right)$ cells were injected in the mammary fat pads of female nu/nu mice (Department of Experimental Oncology, MD Anderson), whereas HT29 $\left(2 \times 10^{6}\right)$ and ACHN $\left(1 \times 10^{7}\right)$ cells were injected subcutaneously. BT474 cell suspensions were mixed with Matrigel (BD Biosciences). Mice bearing ZR751, MCF7, BT474 Par, and BT474 RR xenografts were implanted with $17 \beta$-estradiol pellets (Innovative Research of America) subcutaneously. In a single agent treatment with rapamycin BT474 Par and BT474 RR xenografts mice were randomized into 4 groups (vehicle, rapamycin $1 \mathrm{mg} / \mathrm{kg}$, rapamycin $4 \mathrm{mg} / \mathrm{kg}$, or rapamycin $10 \mathrm{mg} / \mathrm{kg}$, once weekly by intraperitoneal injection, $\mathrm{n}=8$ ). ACHN, HT29, MDA-MB-231, MCF7, and ZR75-1 xenograft mice were randomized into 4 groups (vehicle for everolimus (RAD001), vehicle for MLN0128, everolimus $10 \mathrm{mg} / \mathrm{kg}$ x 5 weekly (oral gavage), MLN0128 $1 \mathrm{mg} / \mathrm{kg}$ x 5 weekly (oral gavage), $n=8-10$ ). Tumor volumes were calculated as previously described [54]. Mice were euthanized 24 hours after the last treatment and the tumors were flash-frozen.

\section{Statistical Analysis}

For in vitro studies, comparisons between two groups were performed using the Student's t-test. All in vitro experiments were performed at least three times. For in vivo studies, comparisons between control and treatment groups were performed by using Mann-Whitney $\mathrm{U}$. Data were presented as means $\pm \mathrm{SE}$.

\section{REFERENCES}

1. Meric-Bernstam F and Gonzalez-Angulo AM. Targeting the mTOR signaling network for cancer therapy. J Clin Oncol. 2009; 27(13):2278-2287.

2. Akcakanat A, Zhang L, Tsavachidis S and Meric-Bernstam F. The rapamycin-regulated gene expression signature determines prognosis for breast cancer. Mol Cancer. 2009; $8: 75$.

3. Meric-Bernstam F, Akcakanat A, Chen H, Do KA, Sangai T, Adkins F, Gonzalez-Angulo AM, Rashid A, Crosby K, Dong M, Phan AT, Wolff RA, Gupta S, Mills GB and Yao J. PIK3CA/PTEN mutations and Akt activation as markers of sensitivity to allosteric mTOR inhibitors. Clin Cancer Res. 2012; 18(6):1777-1789.

4. Vivanco I and Sawyers CL. The phosphatidylinositol 3 -Kinase AKT pathway in human cancer. Nat Rev Cancer. 2002; 2(7):489-501.

5. Guertin DA and Sabatini DM. Defining the role of mTOR in cancer. Cancer Cell. 2007; 12(1):9-22.

6. Wang L, Harris TE and Lawrence JC, Jr. Regulation of proline-rich Akt substrate of $40 \mathrm{kDa}$ (PRAS40) function by mammalian target of rapamycin complex 1 (mTORC1)-mediated phosphorylation. J Biol Chem. 2008; 283(23):15619-15627.

7. Wullschleger $\mathrm{S}$, Loewith $\mathrm{R}$ and Hall MN. TOR signaling in growth and metabolism. Cell. 2006; 124(3):471-484.

8. Jastrzebski K, Hannan KM, Tchoubrieva EB, Hannan $\mathrm{RD}$ and Pearson RB. Coordinate regulation of ribosome biogenesis and function by the ribosomal protein S6 kinase, a key mediator of mTOR function. Growth Factors. 2007; 25(4):209-226.

9. Sengupta S, Peterson TR and Sabatini DM. Regulation of the mTOR complex 1 pathway by nutrients, growth factors, and stress. Mol Cell. 2010; 40(2):310-322.

10. Tremblay F, Brule S, Hee Um S, Li Y, Masuda K, Roden M, Sun XJ, Krebs M, Polakiewicz RD, Thomas G and Marette A. Identification of IRS-1 Ser-1101 as a target of S6K1 in nutrient- and obesity-induced insulin resistance. Proc Natl Acad Sci U S A. 2007; 104(35):14056-14061.

11. Jacinto E, Facchinetti V, Liu D, Soto N, Wei S, Jung SY, Huang Q, Qin J and Su B. SIN1/MIP1 maintains rictormTOR complex integrity and regulates Akt phosphorylation and substrate specificity. Cell. 2006; 127(1):125-137.

12. Yang Q, Inoki K, Ikenoue $\mathrm{T}$ and Guan KL. Identification of Sin1 as an essential TORC2 component required for complex formation and kinase activity. Genes Dev. 2006; 20(20):2820-2832.

13. Pearce LR, Huang $X$, Boudeau J, Pawlowski R, Wullschleger S, Deak M, Ibrahim AF, Gourlay R, Magnuson MA and Alessi DR. Identification of Protor as a novel Rictor-binding component of mTOR complex-2. Biochem J. 2007; 405(3):513-522.

14. Frias MA, Thoreen CC, Jaffe JD, Schroder W, Sculley T, Carr SA and Sabatini DM. mSin1 is necessary for Akt/ PKB phosphorylation, and its isoforms define three distinct mTORC2s. Curr Biol. 2006; 16(18):1865-1870.

15. Sarbassov DD, Ali SM, Kim DH, Guertin DA, Latek RR, Erdjument-Bromage H, Tempst P and Sabatini DM. Rictor, a novel binding partner of mTOR, defines a rapamycininsensitive and raptor-independent pathway that regulates 
the cytoskeleton. Curr Biol. 2004; 14(14):1296-1302.

16. Hresko RC and Mueckler M. mTOR.RICTOR is the Ser473 kinase for Akt/protein kinase B in 3T3-L1 adipocytes. J Biol Chem. 2005; 280(49):40406-40416.

17. Sarbassov DD, Guertin DA, Ali SM and Sabatini DM. Phosphorylation and regulation of Akt/PKB by the rictormTOR complex. Science. 2005; 307(5712):1098-1101.

18. McAuliffe PF, Meric-Bernstam F, Mills GB and GonzalezAngulo AM. Deciphering the role of PI3K/Akt/mTOR pathway in breast cancer biology and pathogenesis. Clin Breast Cancer. 2010; 10 Suppl 3:S59-65.

19. Chan S, Scheulen ME, Johnston S, Mross K, Cardoso F, Dittrich C, Eiermann W, Hess D, Morant R, Semiglazov V, Borner M, Salzberg M, Ostapenko V, Illiger HJ, Behringer D, Bardy-Bouxin N, et al. Phase II study of temsirolimus (CCI-779), a novel inhibitor of mTOR, in heavily pretreated patients with locally advanced or metastatic breast cancer. J Clin Oncol. 2005; 23(23):5314-5322.

20. Shi Y, Yan H, Frost P, Gera J and Lichtenstein A. Mammalian target of rapamycin inhibitors activate the AKT kinase in multiple myeloma cells by up-regulating the insulin-like growth factor receptor/insulin receptor substrate-1/phosphatidylinositol 3-kinase cascade. Mol Cancer Ther. 2005; 4(10):1533-1540.

21. O'Reilly KE, Rojo F, She QB, Solit D, Mills GB, Smith D, Lane H, Hofmann F, Hicklin DJ, Ludwig DL, Baselga J and Rosen N. mTOR inhibition induces upstream receptor tyrosine kinase signaling and activates Akt. Cancer Res. 2006; 66(3):1500-1508.

22. Quek R, Wang Q, Morgan JA, Shapiro GI, Butrynski JE, Ramaiya N, Huftalen T, Jederlinic N, Manola J, Wagner AJ, Demetri GD and George S. Combination mTOR and IGF1R inhibition: phase I trial of everolimus and figitumumab in patients with advanced sarcomas and other solid tumors. Clin Cancer Res. 2011; 17(4):871-879.

23. Sparks CA and Guertin DA. Targeting mTOR: prospects for mTOR complex 2 inhibitors in cancer therapy. Oncogene. 2010; 29(26):3733-3744.

24. Feldman ME, Apsel B, Uotila A, Loewith R, Knight ZA, Ruggero D and Shokat KM. Active-site inhibitors of mTOR target rapamycin-resistant outputs of mTORC1 and mTORC2. PLoS Biol. 2009; 7(2):e38.

25. Feldman ME and Shokat KM. New inhibitors of the PI3K-Akt-mTOR pathway: insights into mTOR signaling from a new generation of Tor Kinase Domain Inhibitors (TORKinibs). Curr Top Microbiol Immunol. 2010; 347:241-262.

26. Wang X, Beugnet A, Murakami M, Yamanaka S and Proud CG. Distinct signaling events downstream of mTOR cooperate to mediate the effects of amino acids and insulin on initiation factor 4E-binding proteins. Mol Cell Biol. 2005; 25(7):2558-2572.

27. Gingras AC, Raught B and Sonenberg N. Regulation of translation initiation by FRAP/mTOR. Genes Dev. 2001;
15(7):807-826.

28. Kang MH, Reynolds CP, Maris JM, Gorlick R, Kolb EA, Lock R, Carol H, Keir ST, Wu J, Lyalin D, Kurmasheva RT, Houghton PJ and Smith MA. Initial testing (stage 1) of the investigational mTOR kinase inhibitor MLN0128 by the pediatric preclinical testing program. Pediatr Blood Cancer. 2014; 61(8):1486-1489.

29. Davies JM, Robinson AE, Cowdrey C, Mummaneni PV, Ducker GS, Shokat KM, Bollen A, Hann B and Phillips JJ. Generation of a patient-derived chordoma xenograft and characterization of the phosphoproteome in a recurrent chordoma. J Neurosurg. 2014; 120(2):331-336.

30. Ingels $\mathrm{A}$, Zhao $\mathrm{H}$, Thong AE, Saar M, Valta MP, Nolley R, Santos J and Peehl DM. Preclinical trial of a new dual mTOR inhibitor, MLN0128, using renal cell carcinoma tumorgrafts. Int J Cancer. 2014; 134(10):2322-2329.

31. Guo Y and Kwiatkowski DJ. Equivalent benefit of rapamycin and a potent mTOR ATP-competitive inhibitor, MLN0128 (INK128), in a mouse model of tuberous sclerosis. Mol Cancer Res. 2013; 11(5):467-473.

32. Lorenz MC and Heitman J. TOR mutations confer rapamycin resistance by preventing interaction with FKBP12-rapamycin. J Biol Chem. 1995; 270(46):2753127537.

33. Chen J, Zheng XF, Brown EJ and Schreiber SL. Identification of an 11-kDa FKBP12-rapamycin-binding domain within the 289-kDa FKBP12-rapamycin-associated protein and characterization of a critical serine residue. Proc Natl Acad Sci U S A. 1995; 92(11):4947-4951.

34. Brown EJ, Beal PA, Keith CT, Chen J, Shin TB and Schreiber SL. Control of p70 s6 kinase by kinase activity of FRAP in vivo. Nature. 1995; 377(6548):441-446.

35. Dowling RJ, Topisirovic I, Alain T, Bidinosti M, Fonseca BD, Petroulakis E, Wang X, Larsson O, Selvaraj A, Liu Y, Kozma SC, Thomas G and Sonenberg N. mTORC1mediated cell proliferation, but not cell growth, controlled by the 4E-BPs. Science. 2010; 328(5982):1172-1176.

36. Dilling MB, Germain GS, Dudkin L, Jayaraman AL, Zhang $\mathrm{X}$, Harwood FC and Houghton PJ. 4E-binding proteins, the suppressors of eukaryotic initiation factor 4E, are downregulated in cells with acquired or intrinsic resistance to rapamycin. J Biol Chem. 2002; 277(16):13907-13917.

37. Ilic N, Utermark T, Widlund HR and Roberts TM. PI3Ktargeted therapy can be evaded by gene amplification along the MYC-eukaryotic translation initiation factor 4E (eIF4E) axis. Proc Natl Acad Sci U S A. 2011; 108(37):E699-708.

38. Cope CL, Gilley R, Balmanno K, Sale MJ, Howarth KD, Hampson M, Smith PD, Guichard SM and Cook SJ. Adaptation to mTOR kinase inhibitors by amplification of eIF4E to maintain cap-dependent translation. J Cell Sci. 2014; 127(Pt 4):788-800.

39. Garcia-Martinez JM, Moran J, Clarke RG, Gray A, Cosulich SC, Chresta CM and Alessi DR. Ku-0063794 is a specific inhibitor of the mammalian target of rapamycin (mTOR). 
Biochem J. 2009; 421(1):29-42.

40. Rodrik-Outmezguine VS, Chandarlapaty S, Pagano NC, Poulikakos PI, Scaltriti M, Moskatel E, Baselga J, Guichard $\mathrm{S}$ and Rosen N. mTOR kinase inhibition causes feedbackdependent biphasic regulation of AKT signaling. Cancer Discov. 2011; 1(3):248-259.

41. Mercier I, Camacho J, Titchen K, Gonzales DM, Quann K, Bryant KG, Molchansky A, Milliman JN, Whitaker-Menezes D, Sotgia F, Jasmin JF, Schwarting R, Pestell RG, Blagosklonny MV and Lisanti MP. Caveolin-1 and accelerated host aging in the breast tumor microenvironment: chemoprevention with rapamycin, an mTOR inhibitor and anti-aging drug. Am J Pathol. 2012; 181(1):278-293.

42. Blagosklonny MV. Rapalogs in cancer prevention: antiaging or anticancer? Cancer Biol Ther. 2012; 13(14):13491354.

43. Donehower LA. Rapamycin as longevity enhancer and cancer preventative agent in the context of p53 deficiency. Aging (Albany NY). 2012; 4(10):660-661.

44. Gorre ME, Mohammed M, Ellwood K, Hsu N, Paquette R, Rao PN and Sawyers CL. Clinical resistance to STI571 cancer therapy caused by BCR-ABL gene mutation or amplification. Science. 2001; 293(5531):876-880.

45. Lievre A, Bachet JB, Le Corre D, Boige V, Landi B, Emile JF, Cote JF, Tomasic G, Penna C, Ducreux M, Rougier P, Penault-Llorca F and Laurent-Puig P. KRAS mutation status is predictive of response to cetuximab therapy in colorectal cancer. Cancer Res. 2006; 66(8):3992-3995.

46. Kobayashi S, Boggon TJ, Dayaram T, Janne PA, Kocher O, Meyerson M, Johnson BE, Eck MJ, Tenen DG and Halmos B. EGFR mutation and resistance of non-small-cell lung cancer to gefitinib. N Engl J Med. 2005; 352(8):786-792.

47. Pao W, Miller VA, Politi KA, Riely GJ, Somwar R, Zakowski MF, Kris MG and Varmus H. Acquired resistance of lung adenocarcinomas to gefitinib or erlotinib is associated with a second mutation in the EGFR kinase domain. PLoS Med. 2005; 2(3):e73.

48. Engelman JA, Zejnullahu K, Mitsudomi T, Song Y, Hyland C, Park JO, Lindeman N, Gale CM, Zhao X, Christensen J, Kosaka T, Holmes AJ, Rogers AM, Cappuzzo F, Mok T, Lee $\mathrm{C}$, et al. MET amplification leads to gefitinib resistance in lung cancer by activating ERBB3 signaling. Science. 2007; 316(5827):1039-1043.

49. Mittendorf EA, Wu Y, Scaltriti M, Meric-Bernstam F, Hunt KK, Dawood S, Esteva FJ, Buzdar AU, Chen H, Eksambi S, Hortobagyi GN, Baselga J and Gonzalez-Angulo AM. Loss of HER2 amplification following trastuzumab-based neoadjuvant systemic therapy and survival outcomes. Clin Cancer Res. 2009; 15(23):7381-7388.

50. Forbes SA, Bindal N, Bamford S, Cole C, Kok CY, Beare D, Jia M, Shepherd R, Leung K, Menzies A, Teague JW, Campbell PJ, Stratton MR and Futreal PA. COSMIC: mining complete cancer genomes in the Catalogue of
Somatic Mutations in Cancer. Nucleic Acids Res. 2011; 39(Database issue):D945-950.

51. Brunn GJ, Hudson CC, Sekulic A, Williams JM, Hosoi $\mathrm{H}$, Houghton PJ, Lawrence JC, Jr. and Abraham RT. Phosphorylation of the translational repressor PHAS-I by the mammalian target of rapamycin. Science. 1997; 277(5322):99-101.

52. Hara K, Yonezawa K, Kozlowski MT, Sugimoto T, Andrabi K, Weng QP, Kasuga M, Nishimoto I and Avruch J. Regulation of eIF-4E BP1 phosphorylation by mTOR. J Biol Chem. 1997; 272(42):26457-26463.

53. Moreno A, Akcakanat A, Munsell MF, Soni A, Yao JC and Meric-Bernstam F. Antitumor activity of rapamycin and octreotide as single agents or in combination in neuroendocrine tumors. Endocr Relat Cancer. 2008; 15(1):257-266.

54. Mondesire WH, Jian W, Zhang H, Ensor J, Hung MC, Mills GB and Meric-Bernstam F. Targeting mammalian target of rapamycin synergistically enhances chemotherapy-induced cytotoxicity in breast cancer cells. Clin Cancer Res. 2004; 10(20):7031-7042.

55. Soni A, Akcakanat A, Singh G, Luyimbazi D, Zheng Y, Kim D, Gonzalez-Angulo A and Meric-Bernstam F. eIF4E knockdown decreases breast cancer cell growth without activating Akt signaling. Mol Cancer Ther. 2008; 7(7):1782-1788.

56. Luyimbazi D, Akcakanat A, McAuliffe PF, Zhang L, Singh G, Gonzalez-Angulo AM, Chen H, Do KA, Zheng Y, Hung MC, Mills GB and Meric-Bernstam F. Rapamycin regulates stearoyl CoA desaturase 1 expression in breast cancer. Mol Cancer Ther. 2010; 9(10):2770-2784.

57. McNabb DS, Reed R and Marciniak RA. Dual luciferase assay system for rapid assessment of gene expression in Saccharomyces cerevisiae. Eukaryot Cell. 2005; 4(9):15391549.

58. Wang X and Proud CG. (2007). Methods for Studying Signal $\square$ Dependent Regulation of Translation Factor Activity. In: Jon L, ed. Methods Enzymol: Academic Press), pp. 113-142.

59. Koboldt DC, Zhang Q, Larson DE, Shen D, McLellan MD, Lin L, Miller CA, Mardis ER, Ding L and Wilson RK. VarScan 2: somatic mutation and copy number alteration discovery in cancer by exome sequencing. Genome Res. 2012; 22(3):568-576.

60. McLaren W, Pritchard B, Rios D, Chen Y, Flicek P and Cunningham F. Deriving the consequences of genomic variants with the Ensembl API and SNP Effect Predictor. Bioinformatics. 2010; 26(16):2069-2070.

61. Wang K, Li M and Hakonarson H. ANNOVAR: functional annotation of genetic variants from high-throughput sequencing data. Nucleic Acids Res. 2010; 38(16):e164.

62. Kumar P, Henikoff S and Ng PC. Predicting the effects of coding non-synonymous variants on protein function using the SIFT algorithm. Nat Protoc. 2009; 4(7):1073-1081. 
63. Adzhubei IA, Schmidt S, Peshkin L, Ramensky VE, Gerasimova A, Bork P, Kondrashov AS and Sunyaev SR. A method and server for predicting damaging missense mutations. Nat Methods. 2010; 7(4):248-249.

64. Gonzalez-Perez A and Lopez-Bigas N. Improving the assessment of the outcome of nonsynonymous SNVs with a consensus deleteriousness score, Condel. Am J Hum Genet. $2011 ; 88(4): 440-449$. 